\title{
The Necessity of Minimal Representation of Genericity in a Newly Developed Language, Unish
}

\author{
Sunyoung Park \\ Sejong University, Korea
}

\begin{abstract}
The current study compares generic representations in different languages including English and Korean. It reviews important universal concepts of genericity denotation in languages and compares how genericity is realized in different languages. By comparing different genericity representations in different languages, the current study predicts possible acquisition difficulties. It also suggests difficulties of acquiring English article systems are also caused by the complex nature of article uses. Particularly, using a
\end{abstract}

\footnotetext{
Sunyoung Park

Visiting Professor, Daeyang Humanity College, Sejong University, Korea

Email:sunpark@sejong.ac.kr
}

Received 7 August, 2021; Revised 2 September, 2021; Accepted 17 September, 2021

Copyright (C) 2021 Language Research Institute, Sejong University Journal of Universal Language is an Open Access Journal. All articles are distributed online under the terms of the Creative Commons Attribution Non-Commercial License (http://creativecommons.org/licenses/by-nc/3.0) which permits unrestricted non-commercial use, distribution, and reproduction in any medium, provided the original work is properly cited. 
The Necessity of Minimal Representation of Genericity in a Newly

large corpus data (ICNALE), the current study reveals how L1 Korean L2 English learners use articles when they denote generic terms in their essays. Ample uses of bare Noun Phrase (NP) forms tentatively suggest that (i) probably uses of 'articles' are not necessarily the most efficient way of expressing genericity, and (ii) it can be marked by other grammatical functions, which are more simple and regular. Therefore, the current research argues that NP systems should be simplified and minimally represented in a newly developed language, which by nature will be learners' extra language. In the current research, generic NPs in Unish language is introduced and it suggests that bare noun forms in Unish can denote genericity in a very regular and economical manner. Therefore, it may be easier for leaners to acquire because the configuration process is minimized in the Unish.

Keywords: generic reference, second language acquisition, minimalist representation principle, constructed language, universal language, article system

\section{Introduction}

Many language acquisition studies have agreed that English article system is one of the most notorious features to acquire for L2 leaners (Thomas 1989, Master 1990, Robertson 2000, Ionin et al. 2004, Snape 2013, Park 2014, among many others). While the frequency of article in L1 production is very high in both spoken and written English (Celce-Murcia \& Larsen-Freeman 1999), article usages are not very clear to L2 learners, and sometimes even to the English native speakers. Despite the ample L2 input, even most advanced L2 English leaners often fail to reach a target-like status in terms of article acquisition. The difficulties of English article come from their complex usages of (in)definiteness, genericity, and plurality. It is known that English article is particularly difficult for L2 learners 
without article or article-like system in their mother tongue. The universal meaning of 'genericity' and 'definiteness' are denoted differently in different languages. In fact, according to Dryer (1989), article system is not a common grammatical phenomenon and two thirds of existing natural languages do not have article systems at all including Korean, Chinese, Japanese, and majority of Slavic and Baltic languages). In other words, articleless languages denote the universal meaning of 'genericity' and 'definiteness' in different ways. When certain meaning is denoted differently in two languages, language learners should figure out how the feature is expressed in a new language. And the configuration process becomes more difficult when the two languages are distant. The current study compares how genericity is marked in English and Korean. Then, it analyses large corpus of English essays written by L1 Korean learners of L2 English. Based on the results of the corpus analysis, the current study argues 'no article system' in Unish is very advantageous for the language learners. Artificial languages, by nature, will be learners' additional language and the configuration/remapping process should be minimized as much as possible. Thus, the current study lends supports to the Minimal Representation Principle suggested by Park \& Tak (2017) by arguing $\mathrm{NP}^{1}$ systems in Unish are very regular and economical. The organization of the current paper is as follows. Section 2 discusses denotations of generic references in English and Korean, and Section 3 presents L2 English learners' article usage patterns by analyzing a large corpus data. Section 4 shows generic Noun Phrase representations in Unish language. Section 5 provides

\footnotetext{
1 The following abbreviations are used in this paper: NP (Noun Phrase), ACC (accusative), CEFR (Common European Framework), CL (classifier), DEC (declarative), GEN (generic particle), ICNALE (International Corpus Network of Asian Learners of English), PLU (plural), PRE (present tense), SUB (subject particle).
} 
90 The Necessity of Minimal Representation of Genericity in a Newly

implication and conclusion.

\section{Generic References across Languages}

Genericity is marked differently in different languages. The current section explores how genericity is marked in English and Korean.

\subsection{English}

Genericity has been studied by both linguists and philosophers for the last couple of decades. A number of studies have revealed interesting facts and developed important concepts about genericity. Krifka (1987) developed a very important distinction between generic sentences and generic NPs. In other words, there exist two kinds of genericity in English. Let us briefly review how the two genericities are expressed in English.

Firstly, in terms of generic sentences, they express generalizations of a subject NP as opposed to a particular sentence that states a particular event. Consider the examples in (1).

(1) a. The sun rises in the east.

b. The sun rose in the east this morning.

(Carlson \& Pelletier 1995: 230)

(1a) is a generalization of an event that happens regularly, whereas (1b) states a particular episodic event that happened one time. Thus, (1a) can be said as a generic sentence. As one might expect, in generic/characterizing sentences, since the locus of genericity lies in the sentences or predicates, subject can be any types of NPs. 
(2) a. Kim smokes a cigarette after dinner.

b. A dog is a faithful animal.

c. The potato is highly digestible.

d. Potatoes are served whole or mashed as cooked vegetable. (modified from Carlson \& Pelletier 1995: 3, 8)

Sentences in example (2) are all characterizing generic sentences, and a range of different NPs are used in the subject position. (2a) shows uses of proper noun, (2b) shows indefinite singular, (2c) is definite singular, and (2d) indicates uses of bare plural NP in characterizing generic sentences. What is more complicated is that the semantic meanings behind the uses of nouns are different from each other. For indefinite singular NPs such as 'a dog' in (2b), it is semantically interpreted as a generalization of a dog. Also (2c), 'the potato' has a semantic interpretation of 'the potato' as a kind of Solanum tuberosum (a scientific name for potatoes). The bare plural $\mathrm{NP}$ in (2d) is a sum of individual potato, thus referring to potatoes in general, thus generic.

On the other hand, generic NPs refer to 'a kind' (Carlson \& Pelletier 1995). Consider the examples in (3) below.

(3) a. The potato was first cultivated in South America.

b. Potatoes were introduced into Ireland by the end of the $17^{\text {th }}$ century.

c. * A potato was first cultivated in South America.

(modified from Carlson \& Pelletier 1995: 2)

'The potato' in (3a) and 'potatoes' in (3b) refer to the kind of potato as Solanum tuberosum (a scientific name for potatoes). In other words, 'the potato' in (3a) and 'potatoes' in (3b) do not designate some 
92 The Necessity of Minimal Representation of Genericity in a Newly

specific potatoes. That is to say generic NPs such as definite singular NP forms and bare singular NP forms do not refer to particular object, but they rather refer to a kind. Consider example (3c), indefinite singular nouns are speculated as odd in this sentence. That is because 'a potato' refers to one of the indefinite potatoes in the world rather than a kind of potato. Consider the following examples in (4).

(4) a. Dodos were extinct.

b. The dodo was extinct.

c. * A dodo was extinct.

(modified from Park 2014: 27)

Predicates like 'extinct' require only kind-referring/generic NPs as a subject. Therefore, bare plural forms (dodos) and definite singular forms (the dodo) can be used as a subject. A dodo as in (4c) is regarded as infelicitous for generic readings. Important concepts of generic sentences and generic NPs have been now reviewed. Now, let us consider how genericity is marked in Korean language.

\subsection{Korean}

In Korean, it is widely argued that genericity is closely related to the uses of particle 'nun' (Kim 1991, Lee 1995, Jun 2001, among many others). Particle 'nun' has two main functions: a thematic marker and a contrastive marker. A thematic marker 'nun' is used when the preceding NPs are concerned with old information, whereas a contrastive marker 'nun' is used to denote contrasts between NPs. Generic uses of 'nun' is speculated as a kind of thematic marker (Jun 2001). Based on discourse data, it was asserted that particle 'nun' denotes genericity. In general, particle 'nun' appears after bare singular nouns in generic sentences (Lee 1995). 
(5)

a. Kay-nun cic-nun-ta.

Dog-GEN bark-PRE-DEC

'The dog barks: Dogs bark.'

b. Kay-nun cecmekitongmwul-i-ta.

Dog-GEN mammal-be-DEC

'The dog is a mammal: Dogs are mammals.'

(Lee 1995)

As in (5a) and (5b), particle 'nun' after singular nouns marks genericity in the sentences. In (5a), the subject 'kay' is a generic NP.

Some studies also suggest that plural NPs can be also used before 'nun' to designate generic readings (Kim 2005).

(6) a. Sinsa-tul-un suknyeolul wihae munul yeoleo junda.

Gentleman-PLU-GEN lady-ACC for door open-DEC

'Gentlemen open doors for ladies.'

b. ? Chaeksang-tul-un tari-ka nea-gae-da.

Desk-PLU-GEN leg-SUB four-CL-DEC

'Desks have four legs.'

(Park 2014: 45)

(6a) sentence indicates that particle 'un' ${ }^{2}$ is used after plural nouns. On the other hand, some researchers like Nemoto (2005) argues that only animate plural nouns can be used as generic with particle 'nun', and inanimate plurals such as 'chaeksang (desk)' in (6b) sound odd. According to the examples in (6a) and (6b), animacy seems to play a role on the plurality of NPs. However, to what extent animacy influences on the uses of nouns are not very clear. What is important is that particle 'nun' is used to denote both generic sentences and

2 'un' is a phonetic variation form of particle 'nun'. 
94 The Necessity of Minimal Representation of Genericity in a Newly

generic NPs in Korean.

\subsection{Possible Difficulties Caused by Crosslinguistic Differences}

Sentence structures of genericity in English and Korean were discussed in section 2.1 and 2.2. Let us now compare the generic representations between the two languages.

Table 1. Comparison of NP Uses between English and Korean

\begin{tabular}{|c|c|c|}
\hline & English & Korean \\
\hline Generic Sentences & $\begin{array}{c}\text { bare plural } \\
\text { definite singular } \\
\text { indefinite singular }\end{array}$ & $\begin{array}{l}\text { bare singular } \\
\text { ?bare plural }\end{array}$ \\
\hline Generic NPs & $\begin{array}{c}\text { bare plural } \\
\text { definite singular }\end{array}$ & $\begin{array}{l}\text { bare singular } \\
\text { ?bare plural }\end{array}$ \\
\hline
\end{tabular}

As shown in Table 1, English and Korean are very distant in terms of expressing genericity. Especially for Korean learners who do not have article system in their L1 should understand a range of article uses in relation to their semantic concepts to acquire English genericity. Researchers believe that acquisition becomes more difficult when the representation of linguistic properties is distant. The next section will discuss learner corpus data collected from Korean speaking learners of L2 English.

\section{Corpus Analysis on English Generic NPs}

The current study has briefly analysed a large corpus data called the ICNALE. The reason of analyzing the corpus data is to investigate 
learners' behavior regarding the uses of generic NPs. ICNALE provides data across different proficiency groups, thus one can find developmental patterns of L2 learners. In addition, the ICNALE also provides L1 English data, which can be compared to the learners' performances. ICNLAE divided the participants into 4 bands of A2, B1_1 (B1 low), B1_2 (B1 high), and B2_0 following the Common European Framework (CEFR, Council of Europe, 2001). While ICNALE provides both written and spoken data, the current study only focuses on the written data. For the written task, two topics were given to the participants: (a) It is important for college students to have a part-time job and (b) Smoking should be completely banned at all the restaurants in the country. The ICNALE written data is comprised of 300 written essays with total number of 69,594 words.

In analyzing data, many existing corpus studies have itemized all the NPs found in the text and analysed their uses in relation to the uses of articles. However, the current study has narrowed its scope and analysed only one NP, which occurs most frequently in the text, which is part time job in this case. AntConc 3.5.8. was employed to analyse the data set. The most frequently used nouns were time $(2,024)$, part $(2,025)$, and job $(1,768)$. Thus, the current research chooses to investigate how learners behaved when they wanted to refer to the 'part time job' in their essays. 
The Necessity of Minimal Representation of Genericity in a Newly

Table 2. Usage Rates of NPs Used in the Written Data by Proficiency Level

\begin{tabular}{|c|c|c|c|c|c|}
\hline & $\begin{array}{c}\mathrm{A} 200 \\
(\mathrm{n}=75)\end{array}$ & $\begin{array}{c}\mathrm{B} 1 \_1 \\
(\mathrm{n}=61)\end{array}$ & $\begin{array}{c}\mathrm{B} 1 \_2 \\
(\mathrm{n}=88)\end{array}$ & $\begin{array}{c}\mathrm{B} 2 \_0 \\
(\mathrm{n}=76)\end{array}$ & $\begin{array}{c}\mathrm{L} 1 \mathrm{E} \\
(\mathrm{n}=200)\end{array}$ \\
\hline Bare Plural & $\begin{array}{c}12 \% \\
(36)\end{array}$ & $\begin{array}{c}10.6 \% \\
(36)\end{array}$ & $\begin{array}{c}9.3 \% \\
(44)\end{array}$ & $\begin{array}{c}17.1 \% \\
(66)\end{array}$ & $\begin{array}{c}19.42 \% \\
(88)\end{array}$ \\
\hline $\begin{array}{c}\text { Indefinite } \\
\text { Singular }\end{array}$ & $\begin{array}{c}36.6 \% \\
(108)\end{array}$ & $\begin{array}{c}40.6 \% \\
(138)\end{array}$ & $\begin{array}{c}45.0 \% \\
(213)\end{array}$ & $\begin{array}{c}58.2 \% \\
(224)\end{array}$ & $\begin{array}{c}78.58 \% \\
(356)\end{array}$ \\
\hline *Bare Singular & $\begin{array}{c}46.3 \% \\
(139)\end{array}$ & $\begin{array}{c}39.4 \% \\
(134)\end{array}$ & $\begin{array}{c}39.1 \% \\
(185)\end{array}$ & $\begin{array}{c}20.0 \% \\
(77)\end{array}$ & $\begin{array}{c}0 \% \\
(0)\end{array}$ \\
\hline Definite & $\begin{array}{c}5.7 \% \\
\text { Singular }\end{array}$ & $\begin{array}{c}8.8 \% \\
(17)\end{array}$ & $\begin{array}{c}6.6 \% \\
(30)\end{array}$ & $\begin{array}{c}4.4 \% \\
(17)\end{array}$ & $\begin{array}{c}1.76 \% \\
(8)\end{array}$ \\
\hline Definite Plural & $\begin{array}{c}0.0 \% \\
(0)\end{array}$ & $\begin{array}{c}0.6 \% \\
(2)\end{array}$ & $\begin{array}{c}0.0 \% \\
(0)\end{array}$ & $\begin{array}{c}0.3 \% \\
(1)\end{array}$ & $\begin{array}{c}0.2 \% \\
(1)\end{array}$ \\
\hline Total & $\begin{array}{c}100 \% \\
(300)\end{array}$ & $\begin{array}{c}100 \% \\
(340)\end{array}$ & $\begin{array}{c}100 \% \\
(473)\end{array}$ & $\begin{array}{c}100 \% \\
(385)\end{array}$ & $\begin{array}{c}100 \% \\
(453)\end{array}$ \\
\hline \multicolumn{7}{|c|}{} & \multicolumn{3}{|c}{}
\end{tabular}

Table 2 shows learners' article choice patterns when they refer to the 'part time job' in their essays. Learners used bare plural (part time jobs), indefinite singular (a part time job), bare singular (part time job), definite singular (the part time job), and definite plural (the part time jobs). Their usage patterns differ according to their proficiency levels. A2_0 is the lowest level, B2_0 is the highest level, and L1E is a control data from English native speakers.

In all proficiency groups, uses of definite singular and definite plural were very low. In contrast, uses of indefinite singular and bare singular forms are found to be most frequently used. In the previous acquisition studies, in the development process of article acquisition, it has been argued that acquisition of indefinite singular NPs appears at the last stage. However, the result of the current research is rather different from the existing literature. Usage rates of indefinite singular 
are relatively high and L1E group also used 'indefinite singular' forms most frequently. The reason of this phenomenon can be accounted for by the promt in the question sentences: It is important for college students to have a part-time job. As the indefinite NP form, a part time job, was used in the question, it can be interpreted as that the participants repeated the phrase in their production, thus resulting in ample uses of indefinite singular forms. In fact, the NP "have a part time job" was used 248 times and "having a part time job" appeared 99 times in the data set.

Most noticeable feature was the uses of the bare singular forms. The bare singular form is ungrammatical in English unless a noun is uncountable. Despite the ungrammaticality of bare nouns, bare singular forms (part time job) are used most frequently in A2_0 level with $46.3 \%$ usage rates. Furthermore, uses of bare singular forms are comparable to the uses of indefinite singular forms in B1_1 and B1_2 levels by showing $39.4 \%$ and $39.1 \%$, respectively. Furthermore, even the most advanced learners of level B2_0 used bare singular forms quite a lot to refer to the part time job in general by showing $20 \%$ of usage rates. Usage rates of bare plural forms in A2_0, B1_1, B1_2 are moderate and similar between groups by showing $12 \%, 10.6 \%$, and $9.3 \%$, respectively. The highest proficiency group B2_0 showed similar usage rates to that of the native speakers (L1E group) by showing $17.1 \%$ usage rates.

To sum up the results of the current analysis, L2 learners' article usage patterns became similar to that of the native speakers as their proficiency level goes higher. In the meantime, one of the very interesting results is the high usage rates of bare singular forms across the proficiency levels, even in the most advanced learner group of B2_0 level. It can be partly explained by influence of L1, which denotes genericity by using particle 'nun' after bare singular nouns. 
Further analysis is required to verify the role of L1 transfer by comparing data from other L1 backgrounds. The corpus analysis revealed the overuse of bare singular forms and it lends support to the advantages of simplified NP systems in an artificial language. The next section introduces generic NPs in Unish.

\section{Implications for a Newly Constructed}

\section{Language, Unish}

In order to break down the language barrier in the international community, Sejong University has been developing a new artificial language, Unish, for the past couple of decades based on existing natural and artificial languages. Unish is being developed to serve as a common language in the globalized era. Unish research team has been trying to identify 'regular' and 'common' features of languages from fifteen representative languages, including 14 natural languages of English, Spanish, Portuguese, Italian, French, German, Russian, Korean, Chinese, Japanese, Arabic, Hindi, Greek, Latin, and one artificial language, Esperanto. Since Unish has been developed focusing on the regularity and simplicity of the languages, many linguistic features in Unish are designed for learners to acquire conveniently. For example, vocabularies, noun forms, pronouns, tenses, passives, auxiliary verbs and many other grammatical features have been refined and simplified to make it easy for learners to understand and master. Among those features, one of the features that stand out is the NP system. In Section 2 and 3, it was confirmed that nouns with various structures were used to express generic meanings. In this study, we compared English and Korean, showing a significant 
difference between two languages. In English, since various types of noun structures can be used in denoting genericity, learners need to understand a range of complex concepts to figure out which NPs to use before production. In other words, learners firstly need to configure whether the genericity comes from a sentence or an NP, and choose appropriate NPs. On the other hand, Korean language does not have article system and genericity is marked by attaching the particle 'nun' after bare singular nouns. However, it was also argued that only animate nouns can be pluralized to denote generic terms in Korean. That is because plurality is closely related to the animacy in Korean language. As such, one can expect that it will not be easy for L1 Korean learners to acquire generic terms in English under the premise that they are influenced by their mother tongue, which do not have articles.

The forementioned predictions are confirmed by the results of the corpus analysis. The results showed that even the highest level learners still incorrectly used the bare singular NP form, which can be considered the basic form of nouns. Through a comparative study of the two languages and the difficulties of learning for learners, it is necessary to consider simplifying the noun system in a newly constructed language. Park \& Chin (2020) reviewed NPs in Unish in terms of representations of (in)definiteness. It was argued that Unish NPs do not divide singular and plural nouns dichotomously. Default forms of nouns are considered to be bare singular forms and plurality can be optionally marked by adding 's' after nouns. Of course, the two forms are regarded as grammatical in Unish. 
(7)
a. I hav book. I have book 'I have a book(s).'
b. I hav only un book. I have only one book 'I have only one book.'
c. I buyed books. I buy-PAST book-PL 'I bought books.'

As in (7a), bare noun 'book' can refer to 'a book' or 'some books'. The numbers of nouns do not have to be overtly marked in Unish, and they can be optionally chosen by the speaker according to their intension. When the speaker wishes to clearly mark the numbers, they can use 'un' can preceed nouns to mark singularity as in (7b). Likewise, one can add 's' after the noun to denote plurality of nouns as in (7c). As was seen in example (7a)-(7c), NP uses are flexible in terms of marking singularity and plurality. Further to this study, I argue that genericity can be also minimally represented without any articles in Unish. Consider example (8) for characterizing generic sentences in Unish.

(8) a. Dog bark. dog bark 'A dog/ The dog/ Dogs bark.'

b. Dog be smart. dog be smart 'A dog/ The dog/ The dogs is(are) smart.'

In Unish as in (8a) and (8b), 'bare singular form' is used in generic sentences. And example (9) displays generic NPs in Unish. 
(9) a. Dodo be extint. dodo be extinct 'The dodo/ Dodos is(are) extinct.'

b. Potato beed introdused by end of teseme century. Potato be introduced by the end of $17^{\text {th }}$ century 'Potatoes/the potato were/was introduced into Ireland by the end of the 17 th century.'

c. Gentlman open door for ladi. gentleman open (a) door(s) for lady(ies) 'Gentlemen open doors for ladies.'

Underlined NPs in (9a)-(9c) sentences display uses of generic NPs in Unish. Singular nouns can be used as generic NPs as an unmarked form. In addition, in Unish, animacy does not play a role in deciding plurality of nouns used to refer generic referent. So far, we have seen the simplicity and regularity of NPs in a newly constructed language, Unish. Further to the previous study of Park \& Chin (2020), where discussed regular denotation of (in)definiteness in Unish, the current study has revealed the simplicity of generic NP uses in Unish.

\section{Concluding Remarks}

The current research has conducted crosslinguistic analysis between English and Korean in terms of generic representations. It clearly presented genericity was realized differently in English and Korean. English expresses generic sentences and generic NPs through various article uses and Korean marks genericity via particle 'nun'. By analyzing corpus data, surprisingly, it was revealed that even learners in a high proficiency group incorrectly overused 'bare 
102 The Necessity of Minimal Representation of Genericity in a Newly

singular' NP forms. As such, acquisition of article systems poses (singular) great difficulties to L2 language learners, and the current study tentatively suggested a more simplified way of expressing genericity in the newly developed language. Kwak (2003) believes that an artificial language would be easier for learners to acquire on the premise that the language is made with an emphasis on the regularity based on commonalities of existing multiple natural and artificial languages. Park \& Chin (2020) revealed the simple and regular article system in Unish in terms of denoting (in)definiteness. Further to the previous study, the current study suggested a simple way of presenting genericity in Unish by using 'bare NPs'. Expressing both generic sentences and generic NPs via 'bare singular NPs' in Unish is supporting the claim of Minimal Representation Principle (Park \& Tak 2017).

\section{References}

Carlson, G. \& F. Pelletier. 1995. The Generic Book. Chicago, IL: The University of Chicago Press.

Celce-Murcia, M. \& D. Larsen-Freeman. 1999. The Grammar Book: An ESL/EFL Teacher's Course. 2nd edition. Boston, MA: Heinle $\&$ Heinle.

Council of Europe. 2001. Common European Framework of Reference for Languages: Learning, Teaching, Assessment. Cambridge: Press Syndicate of the University of Cambridge.

Dryer, M. 1989. Article-Noun Order. Chicago Linguistic Society 25, 83-97.

Ionin, T. et al. 2004. Article Semantics in L2 Acquisition: The Role of Specificity. Language Acquisition 12.1, 3-69.

Jun, Y. 2001. Clausal Structure and Cyclic Mapping Hypothesis for 
Generic Sentences in Korean. Studies in Generative Grammar 11.2, 275-302.

Kim, C. 2005. The Korean Plural Marker Tul and Its Implications. Ph.D. Dissertation, University of Delaware.

Kim, H. 1991. Teaching English Definite Article Usage to Koreans. $\mathrm{Ph} . \mathrm{D}$. Dissertation, University of California.

Krifka, M. 1987. An Outline of Genericity. Paper presented at the Seminar für Natürlich-Sprachliche Systeme, Universität Tübingen, Tubingen, Germany.

Kwak, E. 2003. Comparisons between Pidgins and 'Unish'. Journal of Universal Language 4.1, 17-31.

Lee, I. 1995. An Analysis of Generic Expressions in Situation Semantics. Proceedings of the 10th Pacific Asia Conference on Language, Information and Computation 19-28. City University of Hongkong.

Master, P. 1990. Teaching the English Articles as a Binary System. TESOL Quarterly 24.3, 461-478.

Nemoto, N. 2005. On Mass Denotations of Bare Nouns in Japanese and Korean. Linguistics 43.2, 383-413.

Park, S. 2014. L2 Acquisition of Genericity in English Articles: The Case of Korean Adult Learners of L2 English. Ph.D. Dissertation, University of Sheffield.

Park, S. \& J. Tak. 2017. Articles in Natural Languages and Artificial Languages. Journal of Universal Language 18.1, 105-127.

Park, S. \& S. Chin. 2020. Examining the Irregularities of Articles and Introducing Minimized NP Systems in Unish. Journal of Universal Language 21.1, 69-88.

Robertson, D. 2000. Variability in the Use of the English Article System by Chinese Learners of English. Second Language Research 16.2, 135-172.

Snape, N. 2013. Japanese and Spanish Adult Learners of English: L2 
104 The Necessity of Minimal Representation of Genericity in a Newly

Acquisition of Generic Reference. Studies in Language Sciences: Journal of the Japanese Society for Language Science 12, 70-94. Thomas, M. 1989. The Acquisition of English Articles by First- and Second-Language Learners. Applied Psycholinguistics 10, 335355. 